\title{
Impact of cognitive-behavioral therapy on daily living skills of high functioning autistic children with anxiety disorders
}

\author{
ATALLAH KHALAF ALENEZI ${ }^{1, \boldsymbol{v}}$, KHADIGA ABD-ELGIED GOMEA HASSAN ${ }^{1,2}$, \\ TAHANY EL-SAYED EL-SAYED AMR ${ }^{1,3}$, ABDULELLAH ALSOLAIS ${ }^{4}$ \\ ${ }^{1}$ College of Applied Medical Sciences at Shaqra, Shaqra University. Shaqra, Saudi Arabia. Tel./fax. +966-55-5182868, vemail: atta@ su.edu.sa \\ ${ }^{2}$ Department of Pediatric Nursing, Faculty of Nursing, Port Said University, Port Said, Egypt \\ ${ }^{3}$ Department of Maternal and Newborn Health Nursing, Faculty of Nursing, Menoufia University, Egypt \\ ${ }^{4}$ College of Applied Medical Sciences at Dawadmi, Shaqra University. Shaqra, Saudi Arabia
}

Manuscript received: 5 August 2020. Revision accepted: 17 January 2021.

\begin{abstract}
Alenezi AK, Hassan KAG, Amr TEE, Alsolais A. 2021. Impact of cognitive-behavioral therapy on daily living skills of high functioning autistic children with anxiety disorders. Nusantara Bioscience 13: 41-46. Cognitively Behavioral Therapy (CBT) is a psychotherapeutic intervention that is used to improve mental health. It is known to have positive effect on the daily living skills of autistic children with anxiety disorders. The aim of the current study was to evaluate the effect of cognitive-behavioral therapy on daily living skills of high functioning autistic children with anxiety disorders. A Quasi-experimental research design was adopted in this research. A purposive sample of 100 autistic children (50 in intervention group and 50 in control group) aged between 7-8 years were included in this study. Three main tools were used: Vineland Adaptive Behavior Scale used to measure the everyday living skills of children, Parent-Child Interaction Questionnaire (PACHIQ), and Diagnostic and Statistical Manual of Mental Disorders (DSM-V) for assessing anxiety disorder in children and adolescents 6-18 years. The results showed an improvement in children's daily life skills and slight reductions in caregiver's participation in the daily life skills of children. There was a significant difference between intervention group and control groups $(\mathrm{p}<0.001)$. The current results exhibit that CBT may help in increasing autistic children's independence towards daily living skills.
\end{abstract}

Keywords: Anxiety disorders, autistic disorders, cognitive behavioral therapy, daily living skills

\section{INTRODUCTION}

Autism Disorders (AD) is a persistent deficit social conversation, and social interaction as manifested by lack of mutual conversation and emotional reciprocity, lack of non verbal communication, and lack of developing, sustaining, and emphatic relationship (DSM-5 2013). The cause of autism is unknown. However, a lot of predisposing agents, ecological and biological factors and physical defects, have been associated with autism.

About eighty percent of children with autism have anxiety disorders (Duvekot et al. 2017). Some researchers reported that anxiety disorders interfere with daily living practice; so autistic children are more liable to have poorly developed on daily self-care which makes them more needed for suitable intervention (Bishop et al. 2013). A recent study suggested that children who are fully dependent on their parents in basic daily self-care are at high risk to remain anxious during their childhood life (Huffman et al. 2011). Many strategies have been used to improve clinical features of autism such as promoting socialization and communication with others. Till now, there is no effective intervention for improving basic daily life activity for a child with high function autism, who has seventy or more degrees of an intelligence quotient (Gillis et al. 2016). Basic daily life activities are essential tasks for human survival, which cover daily care, composed of individual skills, all activities in house or school and community (Huffman et al. 2011). In usual autistic children do not carry out daily self-activity even if they are able to do it.

Most mothers mention several difficulties in training daily life activities for their children suffering from autism (Gillis et al. 2016; Lord et al. 2005). Family-based cognitive-behavioral therapy is an effective intervention for managing anxiety disturbances in well-child and child with autism (Scherer and Dawson 2011). CBT is an intervention model in which new skills are established by enhancing the child and his family through logic and convincing manner and Socratic questioning (Stone et al. 2010). Hence, the current study examines the impact of the primary parent-based CBT intervention on parental perceptions of daily life skills of the child with autism and synchronous anxiety disturbances.

\section{MATERIALS AND METHODS}

\section{Study design}

A non-randomized Quasi-experimental pretest-posttest design was used in this study. The impact of primary parent-based CBT on parental perceptions of daily life skills of the child with autism and synchronous anxiety disturbances was determined. 


\section{Setting and sample}

This study was carried out in Al Amal Complex for Mental Health in Dammam City, Saudi Arabia. The intervention took place between 20 October 2018 to 16 April 2019. A sample of 100 children, aged between 7 to 13 years were included in this study.

\section{Ethical consideration}

A written informed consent was obtained from manager of the facility and parents of children (mostly their mothers), who was primarily accountable for supervision of the children's everyday skills and were willing to participate in this study. Before conducting the study, confidentiality and anonymity of the children were assured during collection of the data. Parents of children were assured that the data will not be reused in another research without their consent. The aim of this study was explained to members of the facility, who were directly associated with children.

\section{Subjects and selection method}

The sample used in this study were children suffering from autism, who were visiting for follow-up at Al Amal Complex for Mental Health in Dammam city, Saudi Arabia.

\section{Inclusion criteria}

Autistic children, Asperger disorders or Pervasive Developmental Disorder - Not Otherwise Specified. Autistic children suffering from separation anxiety or social phobia, or obsessive-compulsive disorder.

\section{Exclusion criteria}

Autistic children their verbal Intelligence Quotient less than 70. Autistic children who participated in other behavioral therapy. Autistic children who received psychiatric drugs or changed dosage during the study. Autistic children or parents disable to share in the current study

\section{Research hypothesis}

Children with autism acquire an improvement in basic daily life skills and reductions of parent's participation in daily life skills after CBT intervention.

\section{Method}

Ethical approval was obtained from College of Applied Medical Science at Shaqra and official permission for conducting the study was secured at Al Amal Complex for Mental Health in Dammam city, Saudi Arabia. Upon approval, the daily living skills of children were measured using the Vineland Adaptive Behavior Scale, and the relationship of the child and parent was evaluated with the use of the Parent-Child Interaction Questionnaire (PACHIQ). The researchers developed a suitable intervention program from literature for children with autism and their parents to improved their basic daily skills. This basic daily life skills program was developed to promote child's skills independently (cognition reorganization) that included a) Focusing on child's establishing trust and self-fulfillment (b) Focusing on social customs that enable the child to act alone. c) Giving rewards with each attempt even if the child do simple steps. A hierarchy plan for developing child's daily life skills (gradation of contact) was used. Families were instructed to assist and encourage any attempts from their children towards independence and give their feedback about this new strategy. A pilot study was carried out on 5 children with autism to examine validity of the questionnaires and to test research feasibility, clarity, and objectivity of the tools. The sample included in the pilot study was excluded from the study sample, and necessary modifications were done accordingly.

The sample of 100 autistic children was divided equally into two main groups; intervention and control of 50 children each. The autistic children in the intervention group were divided into five subgroups, with 10 children for each practitioner. There were no dropouts in the study. These practitioners were in the clinically psychiatric training area at College of Applied Medical Science at Shaqra University and they had experience of dealing with autistic children. Practitioners attended 10 hours of primary activity of the intervention, studied management guide, watched videos of CBT, performed management with pilot study children, and attended 10 workshops with clinical researchers who established the program. Practitioners implemented 8 sessions in 8 weeks, session per week for each subgroup in the study group. Each session continued 70 minutes (about 25 minutes with the children and 45 minutes with the mothers /parents) and the treatment fidelity was assessed by researchers.

\section{Instruments}

The study instruments had three tools. The first tool was a structured questionnaire sheet. It included items related to socio-demographic characteristics of children and their families, such as age, child order, occupation, and level of education of their parents. The second tool is The Vineland Adaptive Behaviour Scales, (Vineland-2) (Community-University Partnership for the Study of Children, Youth, and Families 2012) that measures the personality and social skills of individuals from birth through adulthood. Because adaptive behavior refers to an individual's typical performance of daily tasks essential for personality and social adequacy, this scale assesses what the individuals indeed do, not what they are capable to do. The Vineland-2 assesses adaptive behavior in 4 areas: Communication, Daily life Skills, Socialite, and Motor Skills. Additionally, it provides an accumulation mark that epitomizes the person's achievement over 4 areas of investigation (Community-University Partnership for the Study of Children, Youth, and Families 2012).

The third tool is the Parent-Child Interaction Questionnaire (PACHIQ). It assesses how fathers and mothers see the relation with their children (PACHIQParents form), and how the child assesses his/her relation with his/her mother/father (PACHIQ-Children form). It contains 21 elements in the parents form and 25 elements in the children form, about communications strategies and emotional effects (Lange et al., 2002). The researcher 
evaluated children with autism for anxiety disturbance and daily life activities before and immediately after the intervention and at the end of three months from intervention. Diagnostic and Statistical Manual mental disorders (DSM-V) was used to assess anxiety disorder in children and adolescents 6-18 years. This scale composed of 38 sections contains panic somatic, separation anxiety, general anxiety, social phobia, and school phobia (Community-University Partnership for the Study of Children, Youth, and Families 2012). The data was analyzed using $\mathrm{Chi}^{2}$ test using GraphPad Instat software.

\section{RESULT AND DISCUSSION}

Table 1 shows that most $(95 \%)$ of the autistic children were between 7 and 13 years of age. The mean age was 7.1 \pm 1.316 days. As regards to educational level, most of them $(59 \%)$ were at the primary phase. All the autistic children (100\%) had siblings and $3 \%$ of them had affected siblings with autism. Table 2 shows that majority (97\%) of fathers of autistic children had secondary education and majority of them were employed. In addition, most (90\%) of mothers of autistic children had a high level of education and $7 \%$ of them were house-makers. About $86 \%$ of families were in the middle level of income.

Table 2 shows that majority of families of autistic children faced behavioral, emotional, and physical problems. Also, most $(93 \%)$ of them had financial problems. The behavioral and emotional problems were expected. However, such high percentage of physical problems (98\%) seemed to be high. Saudi Arabia is one the richest countries in the world due to natural resources and many of the Saudis live a comfortable life. Surprisingly, about $93 \%$ of the respondents told they have financial issues.

Table 3 shows that there was a statistically significant difference between intervention and control group at preintervention, post-intervention, and at the end of three months from intervention. The intervention produced a significant improvement in daily life activities and this was increased further in the 3-months follow-up $(\mathrm{P}<0.001)$.

Table 4 shows that there was a statistically significant difference between intervention and control group immediately and at the end of three months from intervention $(\mathrm{P}<0.001)$.

Table 1 showed that most $(95 \%)$ of the autistic children were between 7 and 13 years of age. The mean age was 7.1 \pm 1.316 days. As regards to educational level, most of them $(59 \%)$ were at primary phase. All autistic children (100\%) had siblings and $3 \%$ of them had affected siblings with autism. Majority (97\%) of fathers of autistic children had secondary education and the majority of them worked. In addition, most (90\%) of mothers of autistic children had high level of education and $7 \%$ of them were housewives. Also, the comments $(86 \%)$ of families were in the middle level of income. There was no significant difference in the socio-demographic characters between intervention and control group.

Table 1. Socio-demographic characteristics of autistic children and parents

\begin{tabular}{|c|c|c|c|c|c|c|c|}
\hline \multirow{2}{*}{\multicolumn{2}{|c|}{ Items }} & \multicolumn{2}{|c|}{ Intervention group $(\mathrm{n}=50)$} & \multicolumn{2}{|c|}{ Control group $(n=50)$} & \multicolumn{2}{|c|}{ Total $(n=100)$} \\
\hline & & \multirow{2}{*}{$\begin{array}{c}\text { No } \\
2\end{array}$} & \multirow{2}{*}{$\%$} & \multirow{2}{*}{$\begin{array}{c}\text { No } \\
3\end{array}$} & \multirow{2}{*}{$\begin{array}{l}\% \\
6\end{array}$} & \multirow{2}{*}{$\begin{array}{l}\text { No } \\
5\end{array}$} & \multirow{2}{*}{$\frac{\%}{5}$} \\
\hline Age & $\begin{array}{l}\text { 7- less than } 13 \text { years } \\
13-18 \text { years }\end{array}$ & & & & & & \\
\hline \multicolumn{8}{|c|}{ Mean $+/-$ SD $=7.1 \pm 1.316$} \\
\hline \multirow[t]{2}{*}{ Family members } & 3-5 members & 47 & 94 & 49 & 98 & 96 & 96 \\
\hline & \multicolumn{7}{|c|}{ Mean $+/-$ SD $=3.94+/-0.848$} \\
\hline \multirow[t]{2}{*}{ Sex } & Boy & 34 & 68 & 35 & 70 & 69 & 69 \\
\hline & Girl & 16 & 32 & 15 & 30 & 13 & 13 \\
\hline \multirow[t]{2}{*}{ Educational level } & Primary & 31 & 62 & 28 & 56 & 59 & 59 \\
\hline & Preparatory & 19 & 38 & 22 & 44 & 41 & 41 \\
\hline \multirow[t]{2}{*}{ Having sibling } & Yes & 50 & 100 & 50 & 100 & 50 & 100 \\
\hline & No & 0 & 0 & 0 & 0 & 0 & 0 \\
\hline \multirow[t]{2}{*}{ Child order } & $1^{\text {st }}-3^{\text {rd }}$ & 25 & 50 & 43 & 86 & 68 & 68 \\
\hline & $4^{\text {th }}-9^{\text {th }}$ & 25 & 50 & 7 & 14 & 32 & 32 \\
\hline \multirow[t]{2}{*}{ Affected sibling } & Yes & 1 & 2 & 2 & 4 & 3 & 3 \\
\hline & No & 49 & 98 & 48 & 96 & 97 & 97 \\
\hline \multirow[t]{2}{*}{ Father education } & Secondary & 49 & 98 & 48 & 96 & 97 & 97 \\
\hline & High & 1 & 2 & 2 & 4 & 3 & 3 \\
\hline \multirow[t]{2}{*}{ Father occupation } & Do not work & 2 & 10 & 0 & 100 & 98 & 98 \\
\hline & Work & 48 & 90 & 50 & 2 & 1 & 1 \\
\hline \multirow[t]{4}{*}{ Mother education } & Illiterate & 0 & 0 & 1 & 2 & 1 & 1 \\
\hline & Primary & 3 & 15 & 0 & 0 & 3 & 3 \\
\hline & Secondary & 5 & 25 & 1 & 2 & 6 & 6 \\
\hline & High & 42 & 60 & 48 & 96 & 90 & 90 \\
\hline \multirow[t]{2}{*}{ Mother occupation } & Housewife & 3 & 15 & 4 & 20 & 7 & 7 \\
\hline & Work & 47 & 85 & 46 & 80 & 93 & 93 \\
\hline \multirow{3}{*}{ Family income } & Low & 4 & 20 & 3 & 15 & 7 & 7 \\
\hline & Middle & 42 & 60 & 44 & 70 & 86 & 86 \\
\hline & High & 4 & 20 & 3 & 15 & 7 & 7 \\
\hline
\end{tabular}


Table 2. Shows that the majority of families of autistic children faced behavioral, emotional and physical problems. Also, most ( 93\%) of them had financial problems

\begin{tabular}{llcccccc}
\hline Items & & \multicolumn{2}{c}{$\begin{array}{c}\text { Intervention } \\
\text { group }(\mathbf{n = 5 0})\end{array}$} & \multicolumn{2}{c}{$\begin{array}{c}\text { Control } \\
\text { group }(\mathbf{n = 5 0})\end{array}$} & \multicolumn{2}{c}{$\begin{array}{c}\text { Total } \\
(\mathbf{n = 1 0 0})\end{array}$} \\
\cline { 3 - 8 } & & No & \% & No & \% & No & \% \\
\hline Behavioral & Yes & 49 & 98 & 48 & 96 & 47 & 97 \\
problem & No & 1 & 2 & 2 & 4 & 3 & 3 \\
Emotional & Yes & 49 & 98 & 49 & 96 & 48 & 98 \\
problem & No & 1 & 2 & 1 & 4 & 2 & 2 \\
Physical & Yes & 49 & 49 & 49 & 98 & 48 & 98 \\
problems & No & 1 & 1 & 1 & 2 & 2 & 2 \\
Financial & Yes & 46 & 46 & 47 & 85 & 93 & 93 \\
Problems & No & 4 & 4 & 3 & 15 & 7 & 7 \\
\hline
\end{tabular}

\section{Discussion}

This study found that CBT produced improvements in daily living skills of autistic children skills that received cognitive therapy and completed three months program. The CBT performances provide adaptation skills to autistic study group children and reassure the primary parent for helping their children to be more independent. However, it should be noted that factors such as incorrect reports from primary parents may influence the authenticity of the results.

Table 3. Impact of CBT on basic daily life activities of autistic children (Intervention and control groups)

\begin{tabular}{|c|c|c|c|c|c|c|}
\hline \multirow[b]{2}{*}{ Basic activities of daily living } & \multicolumn{2}{|c|}{ PI ${ }^{a}(n-100)$} & \multicolumn{2}{|c|}{$\mathbf{I I}^{\mathrm{b}}(\mathbf{n}-100)$} & \multicolumn{2}{|c|}{ 3months follow up ( $n=99)$} \\
\hline & $\begin{array}{c}\mathbf{I G} \\
\mathbf{N}=\mathbf{5 0}(\%)\end{array}$ & $\begin{array}{c}\mathbf{C G}^{\mathbf{d}} \\
\mathbf{N}=\mathbf{5 0}(\%)\end{array}$ & $\begin{array}{c}\text { IG } \\
\mathbf{N}=\mathbf{5 0}(\%)\end{array}$ & $\begin{array}{c}\mathbf{C G} \\
\mathrm{N}=\mathbf{5 0}(\%)\end{array}$ & $\begin{array}{c}\text { IG } \\
\mathbf{N}=\mathbf{5 0}(\%)\end{array}$ & $\begin{array}{c}\text { CG } \\
\mathrm{N}=49(\%)\end{array}$ \\
\hline \multicolumn{7}{|l|}{ Bathing and showering: } \\
\hline Need no support & 0 & 0 & 0 & 0 & 0 & 0 \\
\hline Slight support & $8(16)$ & $5(10)$ & $42(84)$ & $5(10)$ & $38(76)$ & $4(8.2)$ \\
\hline \multirow[t]{2}{*}{ Complete support } & $42(84)$ & 45(90) & $8(16)$ & 45(90) & $12(24)$ & $45(91.8)$ \\
\hline & \multicolumn{2}{|c|}{$(0.467) \mathrm{P}>0.001$} & \multicolumn{2}{|c|}{$(6.568) * \mathrm{P}<0.001$} & \multicolumn{2}{|c|}{$(7.451)^{*} \mathrm{P}<0.001$} \\
\hline \multicolumn{7}{|l|}{ Dressing: } \\
\hline Need no support & 0 & 0 & 0 & 0 & 0 & 0 \\
\hline Slight support & $38(76)$ & $35(70)$ & $45(90)$ & $35(70)$ & $40(80)$ & $33(67.3)$ \\
\hline \multirow[t]{2}{*}{ Complete support } & $12(24)$ & $15(30)$ & $5(10)$ & $15(30)$ & $10(20)$ & $16(32.7)$ \\
\hline & \multicolumn{2}{|c|}{$(0.346) \mathrm{P}>0.001$} & \multicolumn{2}{|c|}{$(3.851) * \mathrm{P}<0.001$} & \multicolumn{2}{|c|}{$(7.695) * \mathrm{P}<0.001$} \\
\hline \multicolumn{7}{|l|}{ Self- feeding: } \\
\hline Need no support & 0 & 0 & 0 & 0 & 0 & 0 \\
\hline Slight support & $15(30)$ & $10(20)$ & $42(84)$ & $10(20)$ & $30(60)$ & $10(20.4)$ \\
\hline \multirow{2}{*}{ Complete support } & $35(70)$ & $40(80)$ & $8(16)$ & $40(80)$ & $20(40)$ & $39(79.6)$ \\
\hline & \multicolumn{2}{|c|}{$(0.717) \mathrm{P}>0.001$} & \multicolumn{2}{|c|}{$(5.724) * \mathrm{P}<0.001$} & \multicolumn{2}{|c|}{$(6.603) * \mathrm{P}<0.001$} \\
\hline \multicolumn{7}{|l|}{ Toilet hygiene: } \\
\hline Need no support & 0 & 0 & 0 & 0 & 0 & 0 \\
\hline Slight support & $40(80)$ & $35(70)$ & $43(86)$ & $35(70)$ & $40(80)$ & $35(71.4)$ \\
\hline \multirow[t]{2}{*}{ Complete support } & $10(20)$ & $15(30)$ & $7(14)$ & $15(30)$ & $10(20)$ & $14(28.6)$ \\
\hline & \multicolumn{2}{|c|}{$(0.717) \mathrm{P}>0.001$} & \multicolumn{2}{|c|}{$(5.480) * \mathrm{P}<0.001$} & \multicolumn{2}{|c|}{$(6.474) * \mathrm{P}<0.001$} \\
\hline \multicolumn{7}{|l|}{ Oral care: } \\
\hline Need no support & 0 & 0 & 0 & 0 & 0 & 0 \\
\hline Slight support & $38(76)$ & $37(74)$ & $40(80)$ & $37(74)$ & $30(60)$ & $36(73.5)$ \\
\hline \multirow[t]{2}{*}{ Complete support } & $12(24)$ & $13(26)$ & $10(20)$ & $13(26)$ & $20(40)$ & $13(26.5)$ \\
\hline & \multicolumn{2}{|c|}{$(1.050) \mathrm{P}>0.001$} & \multicolumn{2}{|c|}{$(4.873) * \mathrm{P}<0.001$} & \multicolumn{2}{|c|}{$(5.173) * \mathrm{P}<0.001$} \\
\hline \multicolumn{7}{|l|}{ Total daily living skills } \\
\hline Need no support & 0 & 0 & 0 & 0 & 0 & 0 \\
\hline Slight support & $35(70)$ & $37(74)$ & $45(90)$ & $37(74)$ & $40(80)$ & $37(75.5)$ \\
\hline Complete support & $15(30)$ & 13(26) & $5(10)$ & 13(26) & $10(20)$ & $12(24.5)$ \\
\hline & $(0.406)$ & 001 & $(5.85$ & $<0.001$ & $(9.84$ & 0.001 \\
\hline
\end{tabular}

Note: ${ }^{a}$ PI: Before Intervention, ${ }^{b} \mathrm{II}:$ Post-intervention. ${ }^{\mathrm{c}} \mathrm{IG}$ : Intervention Group ${ }^{\mathrm{d}} \mathrm{CG}$ : Control Group, ${ }^{*}$ Statistically Significant Difference

Table 4. Relation between daily living skills and anxiety disorders among autistic children. (Intervention and control groups)

\begin{tabular}{|c|c|c|c|c|c|c|}
\hline & \multicolumn{2}{|c|}{$B I^{a}(\mathbf{n}-100)$} & \multicolumn{2}{|c|}{$I^{b}(n-100)$} & \multicolumn{2}{|c|}{ At the end of 3months ( $n=99)$} \\
\hline & $\begin{array}{c}\mathbf{C G}^{\mathbf{c}} \\
\mathrm{n}=\mathbf{5 0}(\%)\end{array}$ & $\begin{array}{c}I^{\prime} G^{d} \\
n=50(\%)\end{array}$ & $\begin{array}{c}\mathbf{C G} \\
\mathrm{n}=\mathbf{5 0}(\%)\end{array}$ & $\begin{array}{c}\text { IG } \\
\mathbf{n}=\mathbf{5 0}(\%)\end{array}$ & $\begin{array}{c}\mathrm{CG} \\
\mathrm{n}=\mathbf{4 9}(\%)\end{array}$ & $\begin{array}{c}\text { IG } \\
\mathbf{n}=\mathbf{5 0}(\%)\end{array}$ \\
\hline Total daily living skills & \multicolumn{2}{|c|}{$(0.41) \mathrm{P}>0.001$} & \multicolumn{2}{|c|}{$(5.86) * \mathrm{P}<0.001$} & \multicolumn{2}{|c|}{$(9.85) * \mathrm{P}<0.001$} \\
\hline Parent-Child Interaction & \multirow{2}{*}{\multicolumn{2}{|c|}{$(5.601) * \mathrm{P}<0.001$}} & \multicolumn{2}{|c|}{$(3.449) * \mathrm{P}<0.001$} & \multirow{2}{*}{\multicolumn{2}{|c|}{$\begin{array}{l}(0.406) \quad P>0.001 \\
(0.677) \quad P>0.001\end{array}$}} \\
\hline Anxiety Disorders & & & $(8.177)$ & $<0.001$ & & \\
\hline
\end{tabular}

Note: ${ }^{\text {PII }}$ Before Intervention, ${ }^{\mathrm{b}} \mathrm{II}$ : Post-intervention. ${ }^{\mathrm{c}} \mathrm{SG}$ : Intervention Group ${ }^{\mathrm{d}}$ CG: Control Group, ${ }^{*}$ Statistically Significant Difference 
The primary parents of children in the study group recognized an increase in basic daily living skills that are applied on a regular basis by children, such as oral care, toilet hygiene, dressing, self-feeding, and easy health care, compared with autistic children in control group. Earlier reports suggest that without general external support and guidance, autistic children and their primary parents may find obstacles in developing daily living skills that match children's chronological age (Drahota et al. 2010; Duvekot et al. 2017; Estes et al. 2015).

Additionally, primary parent encouragements, beliefs about intervention and expectations, and intervention obedience can play an important role in the modification of basic daily living skills marks at post-test. CBT needs primary parents to perform a dynamic role in implementing the program. Primary parents should perform correct, regular intervention in self-sufficiently, manner. Reportss of parental belief suggests that managing reliability is significantly accompanied with parent motivation to practice intervention procedures, and parent expectancy of intervention results anticipate parental intervention adherences (Estes et al. 2015; Oswald et al. 2016; National Autistic Society, 2016).

As a final point, primary parents of autistic children in the study group stated that their participation in their child's basic daily self-care skills significantly reduced in comparison with primary parents of autistic children in the control group. A moderate influence was established in pretest and post-test scores related to the participation of primary parents of autistic children in the study group, whereas an insignificant influence was found for primary parents of children in the control group. These are significant outcomes to the CBT Program because primary parent conducts, such as participation in their children's basic daily living skills, have been concerned as an element in the preservation of anxiety and lessened daily living skills (Lord et al. 2005; Drahota et al. 2010). Relating to Wood's model of parental invasiveness, if care-providers take over tasks that children could be accomplished independently, they limit children's mastery and aid dependence and sustained anxiety. Otherwise, children with daily living skill insufficiencies may grow anxious due to their extreme dependence on care-provider. Consequently, reductions in parent invasiveness in their children's basic living skills develop independence and may help in skill achievement and mastery, as well as possibly lowering anxiety level (Duvekot et al. 2017; Estes et al. 2015). In the circumstance, there is a relationship between modifications in anxiety level and daily living changes score, representing various relationships between these concepts. So, elevating daily living skills may be associated with falling in anxiety levels. Fascinatingly, when testing the power of the correlation, correlation is not strong in the study group as opposed to the control group, which would be predictable in a right intervention association. It is evident that primary parental perception of study outcomes of CBT program was seen throughout the study period.

Finally, the study has slight limitations; parent's observations were used to judge the activities of their children as well as their personal participation in the children's self-care skills. As the parents are responsible for the intervention program of CBT, parents' reports might have been subjective by their wishes to achieve the aims of this study. Future studies such as a randomized controlled trial are recommended to support our results.

Parents' CBT program provides statistical and clinically significant in basic daily life activities between autistic children. Parents observed that their autistic children who included in the program were capable to carry out basic daily life activities alone when the program finishes. Parents who included in the program stated that they decreased their participation in their children's personal care, which may provide them with extra time for doing other tasks.

\section{ACKNOWLEDGEMENTS}

The authors are thankful to the staff of Al Amal Complex (Dammam) and staff of College of Applied Medical Sciences for their help.

\section{REFERENCES}

Begeer S, Mandell D, Wijnker-Holmes B, Venderbosch S, Rem D, Stekelenburg F, Koot HM. 2013. Sex differences in the timing of identification among children and adults with autism spectrum disorders. J Autism Dev Disord 43 (5): 1151-1156. DOI: 10.1007/s10803-012-1656-z.

Bishop SL, Hus V, Duncan A, Huerta M, Gotham K, Pickles A, Kreiger A, Buja A, Lund S, Lord C. 2013. Subcategories of restricted and repetitive behaviors in children with autism spectrum disorders. $\mathrm{J}$ Autism Dev Disord 43 (6): 1287-1297. DOI: 10.1007/s10803-0121671-0.

Community-University Partnership for the Study of Children, Youth, and Families. 2012 Review of the Vineland Adaptive Behavior ScalesSecond Edition (Vineland-II). Edmonton, Alberta, Canada.

Diagnostic and statistical manual of mental disorders: DSM-5. 2013. American Psychiatric Publishing, Washington (D.C.).

Drahota A, Wood JJ, Hwang WC, Langley A, Piacentini JC. 2010. Adaptive functioning in school-aged children: Linkages

with trait anxiety and anxiety disorders. J Autism Dev Discord 41 (3): $257-265$.

Duvekot J, Hoopen LW, Slappendel G, van der Ende J, Verhulst FC, van der Sijde A, Greaves-Lord K. 2017. Design and cohort characteristics of the social spectrum study: A multicenter study of the autism spectrum among clinically referred children. J Autism Dev Disord 47 (1): 33-48. DOI: 10.1007/s10803-016-2919-x

Estes A, Zwaigenbaum L, Gu H, St John T, Paterson S, Elison JT, Hazlett H, Botteron K, Dager SR, Schultz RT, Kostopoulos P, Evans A, Dawson G, Eliason J, Alvarez S, Piven J, IBIS network. 2015. Behavioral, cognitive, and adaptive development in infants with autism spectrum disorder in the first 2 years of life. J Neurodev Disord 7 (1): 24. DOI: 10.1186/s11689-015-9117-6.

Gillis JM, Roth ME, Sevlever M. 2016. Personal Hygiene. In J. K. Luiselli (Ed.), Behavioral Health Promotion and Intervention for People with Intellectual and Developmental Disabilities. Springer, Switzerland.

Huffman LC, Sutcliffe TL, Tanner IS, Feldman HM. 2011. Management of symptoms in children with autism spectrum disorders: A comprehensive review of pharmacologic and complementaryalternative medicine treatments. J Dev Behav Pediatr 32 (1): 56-68. DOI: 10.1097/DBP.0b013e3182040acf.

Lange A, Evers A, Jansen H, Dolan C. 2002. PACHIQ-R: The parentchild interaction questionnaire--revised. fam process. 41 (4): 709-722. DOI: $10.1111 /$ j.1545-5300.2002.00709.x. 
Lord C, Wagner A, Rogers S, Szatmari P, Aman M, Charman T, Dawson G, Durand VM, Grossman L, Guthrie D, Harris S, Kasari C, Marcus L, Murphy S, Odom S, Pickles A, Scahill L, Shaw E, Siegel B, Sigman M, Stone W, Smith T, Yoder P. 2005. Challenges in evaluating psychosocial interventions for autistic spectrum disorders. J Autism Dev Disord 35 (6): 695-711. DOI 10.1007/s10803-005-0017-6

Maughan AL, Weiss JA. 2017. Parental outcomes following participation in cognitive behavior therapy for children with autism spectrum disorder. J Autism Dev Disord 47 (10): 3166-3179. DOI 10.1007/s10803-017-3224-z

National Autistic Society. 2016. https://www.autism.org.uk/about/whatis/asd.aspx. 2016
Oswald TM, Winter-Messiers MA, Gibson B, Schmidt AM, Herr CM, Solomon M. Sex Differences in internalizing problems during adolescence in autism spectrum disorder. J Autism Dev Disord 46 (2): 624-636. DOI: 10.1007/s10803-015-2608-1

Scherer SW, Dawson G. 2011. Risk factors for autism: translating genomic discoveries into diagnostics. Hum Genet 130 (1): 123-148. DOI: $10.1007 / \mathrm{s} 00439-011-1037-2$

Stone W, Ruble L, Coonrod E, Hepburn S, Pennington M, Burnette C, Bainbridge NB. 2010. Treatment and Research Institute for Autism Spectrum Disorders $2^{\text {nd }}$ ed. Vanderbilt Kennedy Center, Nashville, TS. 